\title{
MODEL HUBUNGAN TINGGI DAN DIAMETER TAJUK DENGAN DIAMETER SETINGGI DADA PADA TEGAKAN TENGKAWANG TUNGKUL PUTIH (Shorea macrophylla (de Vriese) P.S. Ashton) DAN TUNGKUL MERAH (Shorea stenoptera Burck.) DI SEMBOJA, KABUPATEN SANGGAU Correlation Model Between Height and Crown Diameter with Diameter at Breast Height on Tengkawang Tungkul Putih (Shorea macrophylla (de Vriese) P.S. Ashton) and Tungkul Merah (Shorea stenoptera Burck.) Stand in Semboja, Sanggau Regency
}

\author{
Asef K. Hardjana ${ }^{1)}$ \\ ${ }^{1)}$ Balai Besar Penelitian Dipterokarpa Samarinda \\ Jl. A.W. Syahranie No.68 Sempaja, Samarinda; Telepon. (0541) 206364, Fax (0541) 742298 \\ Email: asef_hardjana@yahoo.co.id \\ Diterima 18 Oktober 2012, direvisi 21 Mei 2013, disetujui 28 Mei 2013
}

\begin{abstract}
Diameter measurement is a relatively easy job, cheap and can get an accurate size, while the measurement of height and canopy tree is a relatively difficult and requires a lot of energy. Modeling the correlation between height and canopy with tree diameter is one of the alternative technic that can make more efficient job to measure the height and diameter of the canopy, and therefore it will provide sufficient data approaching to actual measurement results. Inventory and identification results indicated that tengkawang tungkul is the most dominant tengkawang species in the research area with the density ranging from 63-166 trees/ha, which consists of tungkul putih a total of 128 trees (79,48\%), and tungkul merah much as 47 trees (20,52\%). Furthermore, regression equation of correlation model between height and stem diameter $(d b h)$ can be defined as $T_{t p}=-2,2697+1,2711 d-0,0162 d^{2}\left(n=128 ; R^{2}=0,8177\right.$; $S E=2,1271)$ for tungkul putih, and for tungkul merah is $T_{t m}=-0,0803+0,9334 d-0,0072 d^{2}\left(n=47 ; R^{2}=0,8759 ; S E=\right.$ 1,3891). Equation on the correlation between crown diameter and stem diameter (dbh) was not significantly different, so regression equation models for tungkul putih can be defined as $D T_{t p}=0,7174+0,4360 d-0,0045 d^{2}\left(n=128 ; R^{2}=\right.$ 0,5172; $S E=1,7739)$ and for tungkul merah is $D T_{t m}=3,3287 d^{0,2327}\left(n=47 ; R^{2}=0,0658 ; S E=0,322\right)$.
\end{abstract}

Keywords: Crown diameter, Height, Stem diameter, Tengkawang

\begin{abstract}
ABSTRAK
Pengukuran diameter merupakan pekerjaan yang relatif mudah, murah dan dapat menghasilkan ukuran yang akurat, sedangkan pengukuran tinggi dan tajuk pohon merupakan pekerjaan yang relatif sulit dan membutuhkan banyak tenaga. Penyusunan model hubungan antara tinggi pohon dan tajuk pohon dengan diameter pohon merupakan salah satu alternatif teknis yang dapat mengurangi pekerjaan pihak pengguna dalam mengukur tinggi dan diameter tajuk pohon, sehingga dapat memberikan data yang cukup mendekati dari hasil pengukuran yang sebenarnya. Dari hasil inventarisasi dan identifikasi diketahui bahwa jenis tengkawang tungkul mendominasi jenis tengkawang di lokasi penelitian dengan kerapatan tegakan berkisar 63 - 166 pohon/ha, yang terdiri dari jenis tungkul putih sebanyak 128 pohon (79,48\%), dan tungkul merah sebanyak 47 pohon $(20,52 \%)$. Selanjutnya model regresi hubungan tinggi pohon dengan diameter batang $(\mathrm{dbh})$ yang dapat terbangun adalah $\mathrm{T}_{\mathrm{tp}}=-2,2697+1,2711 \mathrm{~d}-0,0162 \mathrm{~d}^{2}\left(\mathrm{n}=128 ; \mathrm{R}^{2}=0,8177 ; \mathrm{SE}=2,1271\right)$ untuk tungkul putih, sedangkan model regresi untuk tungkul merah adalah $\mathrm{T}_{\mathrm{tm}}=-0,0803+0,9334 \mathrm{~d}-0,0072 \mathrm{~d}^{2}\left(\mathrm{n}=47 ; \mathrm{R}^{2}=0,8759\right.$; $\mathrm{SE}=1,3891)$. Persamaan hubungan diameter tajuk dengan diameter batang $(\mathrm{dbh})$ tidak berbeda nyata, sehingga dapat disusun pula model persamaan regresi untuk tungkul putih yaitu $\mathrm{DT}_{\mathrm{tp}}=0,7174+0,4360 \mathrm{~d}-0,0045 \mathrm{~d}^{2}\left(\mathrm{n}=128 ; \mathrm{R}^{2}=\right.$ $0,5172 ; \mathrm{SE}=1,7739)$ dan tungkul merah yaitu $\mathrm{DT}_{\mathrm{tm}}=3,3287 \mathrm{~d}^{0,2327}\left(\mathrm{n}=47 ; \mathrm{R}^{2}=0,0658 ; \mathrm{SE}=0,322\right)$.
\end{abstract}

Kata kunci : Diameter tajuk, Tinggi, Diameter batang, Tengkawang 


\section{PENDAHULUAN}

Kondisi tegakan di setiap tapak (tempat tumbuh) biasanya digambarkan oleh diameter batang setinggi dada (dbh) dan tinggi pohon yang merupakan gambaran penampilan individu pohon. Peninggi merupakan indikator kualitas tempat tumbuh, jumlah pohon dan luas bidang dasar merupakan penjabaran dari diameter yang mencerminkan kerapatan tegakan, volume tegakan mencerminkan massa kayu, dan luas tajuk yang merupakan penjabaran dari diameter tajuk dapat menggambarkan produksi buah dan semai suatu tegakan (Sumarna, 2008).

Segala informasi di atas dapat diperoleh melalui kegiatan inventarisasi yang biasanya dilaksanakan dengan membuat plot-plot sampel yang diletakkan tersebar merata pada setiap blok tanaman ataupun tempat tumbuh bila di hutan alam. Pengukuran diameter merupakan pekerjaan yang relatif mudah, murah dan dapat menghasilkan ukuran yang akurat, sedangkan pengukuran tinggi dan tajuk pohon merupakan pekerjaan yang relatif sulit dan membutuhkan banyak tenaga. Sehubungan dengan kendala tersebut maka perlu dicari teknik untuk meminimalkan pekerjaan pengukuran tinggi dan tajuk pohon, tanpa mengurangi kelengkapan dan keakuratan data yang disajikan. Jadi, jika tersedia data tinggi dan diameter pohon atau data tajuk dan diameter pohon, maka dapat dirumuskan model hubungan tinggi-diameter atau tajuk-diameter dimana tinggi dan tajuk merupakan fungsi dari diameter.

Pengembangan metode pendugaan potensi hutan, termasuk di dalamnya pendugaan model hubungan antara karakteristik individual pohon seperti tinggi, diameter dan luas tajuk telah banyak dilakukan. Meskipun demikian, penelitian-penelitian tentang pertumbuhan dan hubungan karakteristik pohon masih terus dilakukan karena belum ada model atau formula yang dapat diaplikasikan untuk semua jenis pohon. Hal ini dikarenakan setiap jenis atau kelompok jenis pohon dapat mempunyai pertumbuhan dan ukuran batang yang berbeda sebagai akibat dari interaksi faktor genetik dan lingkungannya (Husch et al., 1972; Huang et al., 2000).

Penyusunan model hubungan antara tinggi pohon dan tajuk pohon dengan diameter pohon merupakan salah satu alternatif teknis yang dapat mengurangi pekerjaan pihak pengguna dalam mengukur tinggi dan diameter tajuk pohon, sehingga dapat memberikan data yang cukup mendekati dari hasil pengukuran yang sebenarnya. Buba (2012) menyatakan bahwa terdapat korelasi positif antara tinggi pohon, diameter tajuk dan tinggi tajuk dengan diameter pohon, sehingga model yang dibentuk dari hubungan ini dapat digunakan untuk mempredikasi ketiga parameter tersebut. Sonmez (2009) juga menyatakan bahwa model hubungan antara diameter batang (dbh) dan diameter tajuk memiliki nilai statistik yang signifikan, sehingga dengan indikator diameter batang dapat memprediksi diameter tajuk.

Hipotesa yang dapat dinyatakan dalam penelitian ini adalah diameter batang (dbh) memiliki fungsi terhadap tinggi pohon dan diameter tajuk tegakan tengkawang.

Dengan beberapa informasi dari penelitian serupa yang dilakukan pada jenis dan lokasi yang berbeda, maka informasi dari hasil penelitian ini menjadi perlu untuk disebarluaskan, terutama yang berkaitan dengan konservasi jenis tengkawang. Oleh karena itu, penelitian ini bertujuan untuk menyusun model hubungan tinggi pohon dan tajuk pohon dengan diameter pohon setinggi dada pada tegakan tengkawang (Shorea spp.), agar dapat memberikan data akurat mengenai produktivitas pertumbuhan dan pendugaan produksi buah dari tegakan tengkawang tersebut.

Kabupaten Sanggau yang dahulunya menjadi salah satu daerah penghasil biji tengkawang terbesar di Kalimantan Barat, merupakan lokasi yang tepat untuk dihidupkan kembali usaha pelestarian tengkawang ini. Dengan kondisi iklim secara umum sering turun hujan dengan rata-rata hari hujan tertinggi terjadi pada bulan November, yaitu 106 hari, sedangkan hari hujan terendah selama 48 hari pada bulan Juli. Angka curah hujan tertinggi juga terjadi pada bulan November sebesar 2.538 
$\mathrm{mm}$, dan curah hujan terendah sebesar 537 pada bulan Februari (BPS Kab. Sanggau, 2010). Informasi ini menjadi sangat penting dalam mendukung proses pertumbuhan dari tegakan tengkawang tersebut hingga menghasilkan buah, serta pengembangannya melalui penelitian yang terpadu.

\section{METODOLOGI PENELITIAN}

Kegiatan penelitian ini dilaksanakan pada tegakan tengkawang di Semboja, Kabupaten Sanggau, Kalimantan Barat. Areal tegakan tersebut masih berada dalam kawasan kota Sanggau, di mana kedepannya dapat menjadi hutan kota. Tegakan yang didominasi jenis tengkawang ini, dahulunya adalah bekas areal penanaman jenis-jenis tengkawang yang merupakan hasil kerjasama teknis antara Indonesia dan Jerman melalui Proyek Pengembangan Hutan Kemasyarakatan (SFDP, Social Forestry Development Project) pada tahun 1991. Dalam kegiatan penelitian ini, pelaksanaan penelitian dimulai pada bulan April hingga Nopember 2011.

Secara umum kondisi topografi relatif datar sampai berbukit dan berawa-rawa. Jenis tanah podsolik merah kuning batuan dan padat yang hampir merata di sebagian besar wilayah Kabupaten Sanggau (BPS Kab. Sanggau, 2010).

Bahan yang digunakan dalam penelitian ini adalah peta lokasi, cat, tinner, baterai dan label. Peralatan yang digunakan adalah phiband, GPS, pita meter, distancemeter, clinometer, kompas, galah berkait dan kamera digital.

Prosedur penelitian yang dilaksanakan mulai dari persiapan, meliputi penyediaan peta kontour atau peta rupa bumi dengan skala 1:50.000 - 1:25.000 atau skala yang tersedia. Peta lokasi penelitian menggambarkan panjang dan lebar areal yang disurvei kemudian dapat dihitung banyaknya pohon yang akan diamati.

Teknik survei yang digunakan adalah dengan cara sensus, dimana setiap bagian areal yang dijumpai tegakan tengkawang dilakukan pendataan. Diperkirakan luas areal $\leq 10$ ha yang dahulunya ditanami jenis tengkawang, tidak semuanya terdapat tegakan tengkawangnya.
Dan areal yang berpotensi terdapat tegakan tengkawang hanya berkisar 5 ha dengan beberapa variasi jenis tengkawang dengan jumlah dan posisinya pada petak tanaman bervariasi pula. Sehingga dengan keterbatasan yang ada dilakukan pembuatan petak ukur sebagai sampel areal untuk melakukan pendataan terhadap objek yang diteliti.

Lokasi pembuatan petak ukur tanaman sebagai objek penelitian dipilih secara sengaja (purposive) untuk memperoleh sebaran diameter seluas mungkin dengan mempertimbangkan ketersediaan tegakan di lapangan. Petak ukur dibuat berbentuk bujur sangkar dengan ukuran $100 \mathrm{~m} \mathrm{x} 100 \mathrm{~m}$ yang ditetapkan sebanyak 2 petak ukur pada lokasi tersebut. Kemudian dilakukan pendataan secara sensus untuk setiap pohon tengkawang yang berada di dalam petak ukur tersebut. Kegiatan ini dilakukan untuk mengetahui sebaran dan keragaman jenis dari tengkawang di kawasan tersebut.

Pengumpulan data dilakukan dengan cara melakukan pengukuran dan pengamatan terhadap dimensi pertumbuhan (diameter dan tinggi pohon) dari jenis tengkawang yang menjadi objek penelitian dalam petak ukur tersebut. Data tersebut merupakan data primer dalam kegiatan penelitian ini. Data primer terdiri dari diameter setinggi dada (dbh), diameter tajuk, tinggi pohon, tinggi bebas cabang dan kerapatan tajuk.

Secara umum pengukuran diameter dilakukan setinggi 1,3 m dengan menggunakan alat phiband, kemudian pengukuran tinggi pohon menggunakan galah berkait dan jika kondisi pohon terlalu tinggi dilakukan pengukuran dengan alat clinometer yang dipadukan dengan alat digital distancemeter untuk mengukur jarak pengukur dan objek. Selanjutnya untuk mengukur diameter tajuk dilakukan dengan menggunakan proyeksi bentuk tajuk yang diukur dalam dua bagian pada proyeksi tersebut dengan menggunakan tongkat atau pita meter, sedangkan untuk data kerapatan tajuk didapatkan melalui pengamatan kondisi tajuk yang saling bertautan maupun jarak antara tajuk. 
Sedangkan pengumpulan data yang dilakukan dengan cara studi literature merupakan kegiatan untuk mendapatkan data sekunder. Data sekunder merupakan data pendukung dalam kegiatan ini. Data sekunder yang dibutuhkan meliputi data iklim makro (curah hujan, jumlah hari hujan selama periode 5 tahun), penggunaan lahan, administrasi wilayah dan topografi.

Dalam analisa vegetasi yang meliputi komposisi jenis dan bentuk atau struktur vegetasi dan inventarisasi hutan untuk menentukan potensi hutan digunakan data diameter dan tinggi. Data diameter digunakan karena dalam hutan terjadi overlap dari tajuk hutan, dimana hubungan antara diameter dan diameter tajuk (cover atau proyeksi tajuk) sangat erat dan berbanding lurus.

Data hasil pengukuran berupa dbh, diameter tajuk dan tinggi pohon dianalisis secara statistik dengan tujuan untuk mendapatkan model hubungan dari ketiga parameter. Penyusunan model hubungan antara dbh, tinggi dan diameter tajuk dilakukan dengan pendekatan regresi, dimana tinggi dan diameter tajuk merupakan fungsi dari diameter. Berikut model persamaan regresi yang dapat menjadi acuan dalam penyusunan model hubungan antara tinggi dan diameter tajuk dengan dbh (Tabel 1). Dari berbagai bentuk persamaan pada Tabel 1, diketahui bahwa model hubungan antara tinggi dan diameter tajuk dengan dbh dapat disusun dengan berbagai bentuk persamaan regresi, baik bentuk linear maupun non-linear.

Namun dari berbagai model dipilih model terbaik berdasarkan nilai keakuratan yang tinggi dan praktis penggunaannya di lapangan. Atau dapat juga dipilih berdasarkan dari nilai keofisien diterminasi $\left(\mathrm{R}^{2}\right)$ terbesar dan nilai galat baku atau standard error (SE) terkecil.

Tabel 1. Persamaan yang digunakan untuk menyusun model hubungan antara tinggi dan diameter tajuk dengan diameter setinggi dada (dbh).

Table 1. The equation used to develop the model of the correlation between height and crown diameter with diameter at breast height (dbh).

\begin{tabular}{ccc}
\hline $\begin{array}{c}\text { Nomor } \\
\text { (Number })\end{array}$ & $\begin{array}{c}\text { Persamaan } \\
(\text { Equation })\end{array}$ & $\begin{array}{c}\text { Bentuk } \\
(\text { Form })\end{array}$ \\
\hline 1. & $\mathrm{y}=\mathrm{b}_{0}+\mathrm{b}_{1}(\mathrm{dbh})$ & Linear \\
2. & $\mathrm{Y}=\mathrm{b}_{0}+\mathrm{b}_{1}(\mathrm{dbh})+\mathrm{b}_{2}\left(\mathrm{dbh}^{2}\right)$ & Quadratic \\
3. & $\mathrm{y}=\mathrm{b}_{0} \ln (\mathrm{dbh})-\mathrm{b}_{1}$ & Logarithmic \\
4. & $\mathrm{y}=\mathrm{b}_{0}(\mathrm{dbh})^{\mathrm{b} 1}$ & Power \\
5. & $\mathrm{y}=\mathrm{b}_{0} \mathrm{e}^{\mathrm{b}(\mathrm{dbh})}$ & Exponential \\
\hline
\end{tabular}

Keterangan: $\mathrm{y}=$ tinggi pohon atau diameter tajuk $(\mathrm{m}) ; \mathrm{x}=$ diameter setinggi dada $(\mathrm{cm}) ; \mathrm{b}_{0}, \mathrm{~b}_{1}=\mathrm{konstanta}$

Sumber: Sonmez Turan (2009).

\section{HASIL DAN PEMBAHASAN}

\section{A. Potensi dan Sebaran Diameter}

Dari hasil inventarisasi pada kedua petak ukur penelitian diketahui bahwa petak ukur 2 memiliki keragaman jenis yang lebih besar dibandingkan petak ukur 1. Pada petak ukur 2 sebanyak 6 jenis tengkawang dengan tingkat kehadiran yang cukup merata dari setiap jenis dan untuk tengkawang tungkul tingkat kehadirannya sebesar 34,24\%. Pada petak ukur 1 hanya terdapat 4 jenis tengkawang dengan tingkat kehadiran didominasi oleh jenis tengkawang tungkul sebesar 93,26\%. Jenisjenis tengkawang yang dijumpai di kedua petak ukur tersebut meliputi tengkawang tungkul (Shorea spp.), layar (S. mecystopteryx Ridl.), terindak ( $S$. seminis (de Viese) v. Slooten), rambai ( $S$. splendida), majau ( $S$. palembanica Miq.) dan pinang ( $S$. pinanga Scheff.). Namun dalam penelitian ini lebih difokuskan pada tegakan tengkawang tungkul putih dan tungkul merah, hal ini dikarenakan jenis tengkawang tersebut buahnya masih menjadi primadona untuk dikonsumsi dan diperjualbelikan di 
wilayah Kalimantan Barat (Winarni et al., 2005).

Dengan keadaan topografi dan lingkungan yang relatif sama, sehingga pembahasan hasil penelitian lebih ditekankan pada jenis karena hasil identifikasi jenis secara total (penggabungan dari petak ukur 1 dan 2) dapat diketahui bahwa jenis tengkawang tungkul mendominasi keberadaannya di kedua petak ukur penelitian, dengan jumlah total sebesar 229 pohon. Dimana kemudian tengkawang tungkul ini diklasifikasikan lagi menjadi dua macam tengkawang tungkul yaitu tengkawang tungkul putih (S. macrophylla (de Vriese) P.S. Ashton) dan tengkawang tungkul merah (Shorea stenoptera Burck). Secara umum tungkul merah memiliki bentuk daun memanjang, warnanya lebih tua, stipula berwarna merah dan permukaan batangnya kurang mulus. Sedangkan untuk tungkul putih memiliki bentuk daun agak membulat, warnanya lebih muda, stipula berwarna hijau keputihan dan permukaan batangnya lebih mulus. Tengkawang tungkul putih mendominasi jenis tengkawang tungkul dalam lokasi penelitian ini dengan jumlah 128 pohon $(79,48 \%)$, sedangkan tengkawang tungkul merah hanya berjumlah 47 pohon $(20,52 \%)$.

Dapat diketahui pula bahwa potensi tegakan tengkawang tungkul di Semboja, Kabupaten Sanggau berkisar antara 63 - 166 pohon/ha dengan posisi tegakan tidak tersebar merata dan hanya terpusat pada beberapa titik tertentu di dalam petak ukur.

Untuk mengetahui potensi sebaran diameter dari tengkawang tungkul putih dan merah, maka dilakukan pengelompokan kelaskelas diameter dengan interval $5 \mathrm{~cm}$, seperti yang tersaji pada Tabel 2 .

Tabel 2. Sebaran diameter tegakan tengkawang tungkul putih (S. macrophylla) dan tungkul merah (S. stenoptera) di lokasi penelitian.

Table 2. Distribution of diameter of tengkawang tungkul putih (S. macrophylla) and tungkul merah (S. stenoptera) in research area.

\begin{tabular}{cccccccccc}
\hline \multirow{2}{*}{$\begin{array}{c}\text { Nomor } \\
\text { (Number) }\end{array}$} & $\begin{array}{c}\text { Jenis } \\
\text { Tengkawang } \\
\text { (Tengkawang } \\
\text { species) }\end{array}$ & $5-9,9$ & $10-14,9$ & $15-19,9$ & $20-24,9$ & $25-29,9$ & $30-34,9$ & $35-39,9$ & $40-44,9$ \\
\cline { 2 - 9 } & Jumlah Pohon Tiap Kelas Diameter (cm) (The number of trees of each diameter class) (N/ha) \\
\hline 1. & Tungkul Putih & 35 & 61 & 46 & 19 & 12 & 3 & 5 & 1 \\
\hline 2. & Tungkul Merah & 17 & 21 & 3 & 5 & 0 & 1 & 0 & 0 \\
\hline
\end{tabular}

Sumber: diolah dari data primer.

Pada Tabel 2 terlihat bahwa kedua jenis tengkawang ini didominasi oleh pohon yang berkelas diameter 10-14,9 $\mathrm{cm}$ dan hanya sedikit yang mencapai kelas diameter di atas $30 \mathrm{~cm}$. Selanjutnya dari sebaran yang terlihat bahwa tungkul putih memiliki kelas sebaran diameter yang lebih banyak dibandingkan dengan tungkul merah, selain itu beberapa tegakan tungkul putih diameter pohonnya sudah melebihi dari $35 \mathrm{~cm}$. Berdasarkan informasi diameter tersebut menunjukkan bahwa pertumbuhan tengkawang tungkul putih lebih cepat dibandingkan tungkul merah. Diameter merupakan salah satu parameter untuk menentukan pertumbuhan suatu tegakan, disamping tinggi pohon.
Pertumbuhan diameter dipengaruhi oleh aktivitas fotosistesis, dimana pertumbuhan diameter berlangsung apabila hasil fotosintesis seperti respirasi, penggantian daun, pertumbuhan akar dan tinggi telah terpenuhi (Davis dan Jhonson, 1987). Oleh karena itu perbedaan pertumbuhan yang terjadi pada kedua jenis tengkawang ini, dapat saja dipengaruhi oleh faktor genetik dan faktor lingkungannya. Setidaknya terdapat tiga faktor lingkungan (tempat tumbuh) dan satu faktor genetik (intern) yang sangat nyata berpengaruh terhadap pertumbuhan diameter maupun tinggi, yaitu kandungan nutrien mineral tanah, kelembaban tanah dan cahaya matahari, serta keseimbangan sifat genetik antara pertumbuhan 
tinggi dan diameter suatu pohon (Davis dan Jhonson, 1987).

Selain dari segi pertumbuhannya yang lebih baik dari tengkawang tungkul merah, untuk sebaran dan jumlah pohon tengkawang tungkul putih juga lebih dominan di lokasi penelitian. Hal ini dapat terjadi mungkin karena pada kondisi awal penanaman lebih banyak ditanam jenis tengkawang tungkul putih dibandingkan dengan jenis tengkawang tungkul merah.

Kondisi sebaran kelas diameter ini juga dapat digambarkan dari bentuk kurva, seperti yang tersaji pada Gambar 1. Seperti yang telah dinyatakan oleh Suyana dan Abdurachman (2006; 2011) bahwa kondisi sebaran diameter yang menyerupai genta atau lonceng merupakan salah satu ciri dari hutan tanaman.

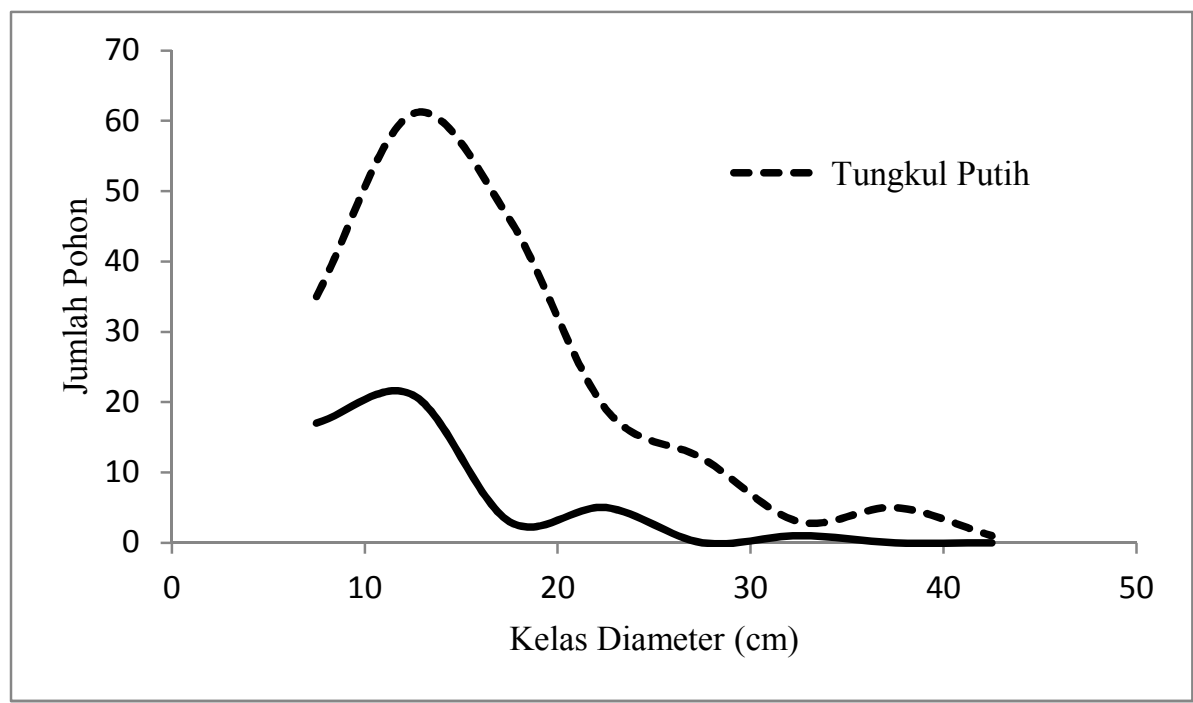

Sumber: diolah dari data primer.

Gambar 1. Kurva sebaran diameter tegakan tengkawang tungkul putih (S. macrophylla) dan tungkul merah (S. stenoptera) di lokasi penelitian.

Figure 1. Curve of diameter distribution of tengkawang tungkul putih (S. macrophylla) and tungkul merah (S. stenoptera) in research area.

Pada Gambar 1 terlihat bahwa kurva sebaran diameter tengkawang tungkul putih masih dapat dikatakan menyerupai genta/lonceng, namun belum bisa dikatakan normal yang sempurna tapi masuk dalam kondisi lognormal. Pada tengkawang tungkul merah kurva sebaran diameternya masih belum dapat dikatakan menyerupai genta/lonceng, sehingga dapat dikatakan bahwa sebaran diameternya belum normal.

Untuk itu dalam pengelolaan selanjutnya perlu dilakukan tindakan silvikultur agar dapat memperoleh hasil yang maksimal, baik itu dari riap, buah dan regenerasi alamnya. Diharapkan kondisi tegakan tengkawang pada areal bekas Proyek Pengembangan Hutan Kemasyarakatan ini secara biometrika bentuk kurva sekitar titik puncak dapat bergeser ke arah sebelah kanan pada sumbu $\mathrm{X}$ yang menyatakan bahwa hasil produksi yang diperoleh menjadi besar.

\section{B. Hubungan Tinggi Pohon dan Diameter Batang}

Kedua petak ukur yang menjadi sampel dalam penelitian ini, memiliki kondisi topografi, tanah dan iklim yang relatif sama. Dengan komposisi jenis didominasi oleh jenis tengkawang tungkul, dimana pada petak ukur pertama ditemukan sebanyak 157 pohon tengkawang tungkul putih dan 7 pohon tengkawang tungkul merah, sedangkan pada petak ukur kedua ditemukan sebanyak 23 pohon tengkawang tungkul putih dan 40 pohon tengkawang tungkul merah. Jadi jumlah total keseluruhan pohon tengkawang tungkul putih yang menjadi sampel berjumlah 180 pohon, 
sedangkan tengkawang tungkul merah berjumlah 47 pohon.

Sebelumnya telah diketahui bahwa kondisi lingkungan lokasi penelitian yang relatif sama, sehingga dalam analisa model dilakukan dengan menggabungkan data dari kedua petak ukur tersebut berdasarkan dari jenisnya. Untuk itu dalam mempertegas data yang dianalisa, terlebih dahulu melakukan analisa statistik untuk kedua variabel ini, yaitu dengan mencari nilai rataan, maksimum, mínimum dan variasinya seperti yang tersaji pada Tabel 3.

Tabel 3. Statistik tinggi pohon dan diameter batang ( $\mathrm{dbh}$ ) pada tegakan tengkawang tungkul putih (S. macrophylla) dan tungkul merah ( $S$. stenoptera) di lokasi penelitian.

Table 3. Statistics of height and stem diameter (dbh) of tengkawang tungkul putih (S. macrophylla) and tungkul merah (S. stenoptera) in research location).

\begin{tabular}{|c|c|c|c|c|c|}
\hline $\begin{array}{l}\text { Nomor } \\
\text { (Number) }\end{array}$ & $\begin{array}{c}\text { Peubah } \\
\text { (Variable) }\end{array}$ & $\begin{array}{l}\text { Rataan } \\
\text { (Mean) }\end{array}$ & $\begin{array}{l}\text { Maksimum } \\
\text { (Maximum) }\end{array}$ & $\begin{array}{l}\text { Minimum } \\
\text { (Minimum) }\end{array}$ & $\begin{array}{c}\text { Variasi } \\
\text { (Variance) }\end{array}$ \\
\hline \multirow[t]{3}{*}{1.} & Tungkul putih & & & & \\
\hline & Tinggi (m) & 12,8176 & 25 & 4 & 24,3499 \\
\hline & Diameter $(\mathrm{cm})$ & 15,6270 & 42,5 & 7 & 49,6837 \\
\hline \multirow[t]{3}{*}{2.} & Tungkul merah & & & & \\
\hline & Tinggi (m) & 10,1956 & 22 & 5 & 15,0942 \\
\hline & Diameter $(\mathrm{cm})$ & 12,4673 & 33 & 7 & 27,1933 \\
\hline
\end{tabular}

Sumber: diolah dari data primer.

Hasil statistik pada Tabel 2 menunjukkan lebar rentang ukuran dari tinggi dan diameter pada kedua jenis tengkawang, nilai tersebut memberikan indikasi adanya variasi yang besar dalam tegakan tengkawang tersebut. Karena adanya perbedaan yang cukup besar antara rataan pada variabel kedua jenis tersebut, menjadikan perlunya dilakukan perlakuan silvikultur pada kondisi tegakan tengkawang tersebut.

Selanjutnya bila ditinjau dari hasil analisa regresi hubungan tinggi pohon dengan diameter batang (dbh) untuk kedua jenis tengkawang tersebut, maka dapat dihasilkan model persamaan regresi seperti pada Gambar 2 dan 3. Model persamaan regresi atau allometrik yang dihasilkan dari hubungan tinggi pohon dengan diameter batang untuk kedua jenis tengkawang tersebut, adalah sebagai berikut :

$\mathrm{T}_{\mathrm{tp}}=-2,2697+1,2711 \mathrm{~d}-0,0162 \mathrm{~d}^{2}$

$\mathrm{T}_{\mathrm{tm}}=-0,0803+0,9334 \mathrm{~d}-0,0072 \mathrm{~d}^{2}$

dimana :

$\mathrm{T}_{\mathrm{tp}}$ : Tinggi pohon tengkawang tunggul putih (m)

$\mathrm{T}_{\mathrm{tm}}$ : Tinggi pohon tengkawang tunggul merah $(\mathrm{m})$

$\mathrm{d}$ : Diameter batang $(\mathrm{dbh})(\mathrm{cm})$
Model persamaan di atas merupakan model yang terpilih dan terbaik dari kelima model yang telah diuji dan di analisa. Hasil analisa model hubungan tinggi pohon dan diameter batang terpilih untuk kedua jenis tengkawang menunjukan hubungan yang cukup erat atau tidak berbeda nyata antara tinggi pohon dengan diameter pohon.

Persamaan hubungan kedua variabel dengan kedua jenis tengkawang mempunyai nilai koefisien determinasi $\left(\mathrm{R}^{2}\right)$ yang cukup tinggi dengan nilai galat baku atau standard error (SE) yang kecil, yaitu $\mathrm{R}^{2}=0,8177$ dan $\mathrm{SE}$ $=2,1271$ untuk jenis tengkawang tungkul putih, sedangkan pada tengkawang tungkul merah memiliki $\mathrm{R}^{2}=0,8759$ dan $\mathrm{SE}=1,3891$.

Disamping itu bila ditinjau dari nilai koefisien korelasi (R) antara tinggi dan diameter batang adalah 0,9043 untuk tengkawang tungkul putih dan 0,9359 untuk tengkawang tungkul merah. Hal ini menunjukkan bahwa hubungan antara tinggi dengan diameter batang setinggi dada adalah sangat nyata, dimana lebih dari $90 \%$ keragaman diameter batang dapat menerangkan keragaman tinggi pohon. 


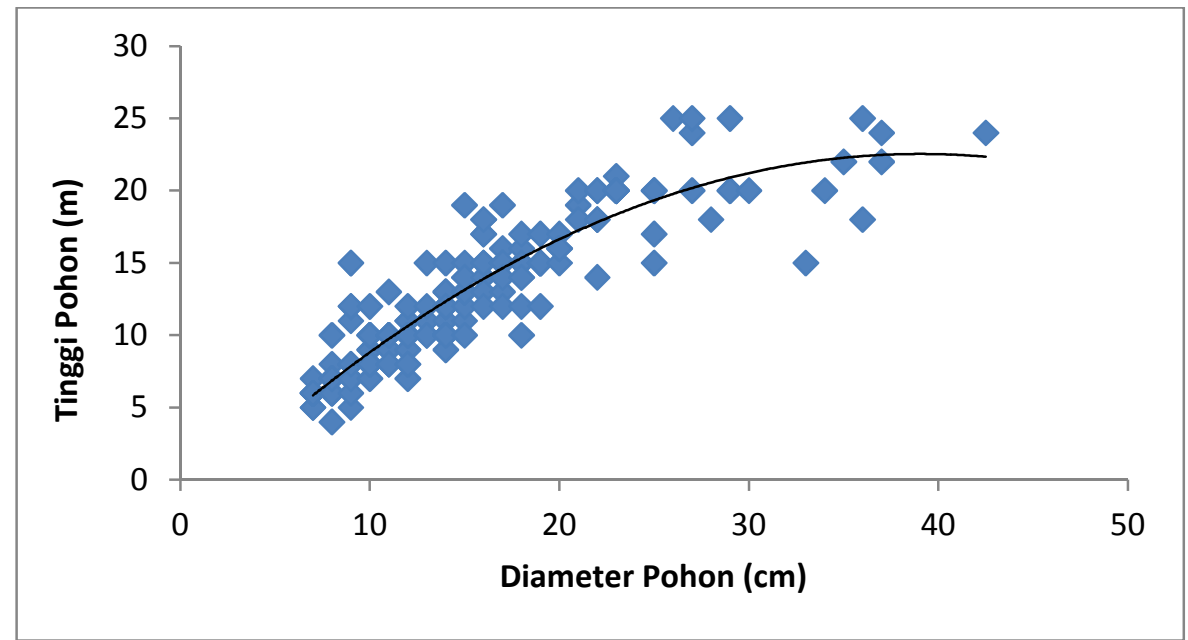

Sumber: diolah dari data primer.

Gambar 2. Model regresi hubungan tinggi pohon dengan diameter batang (dbh) tengkawang tungkul putih (S. macrophylla) di lokasi penelitian.

Figure 2. Regression model of the correlation between height and stem diameter (dbh) of tengkawang tungkul putih (S. macrophylla) in research location.

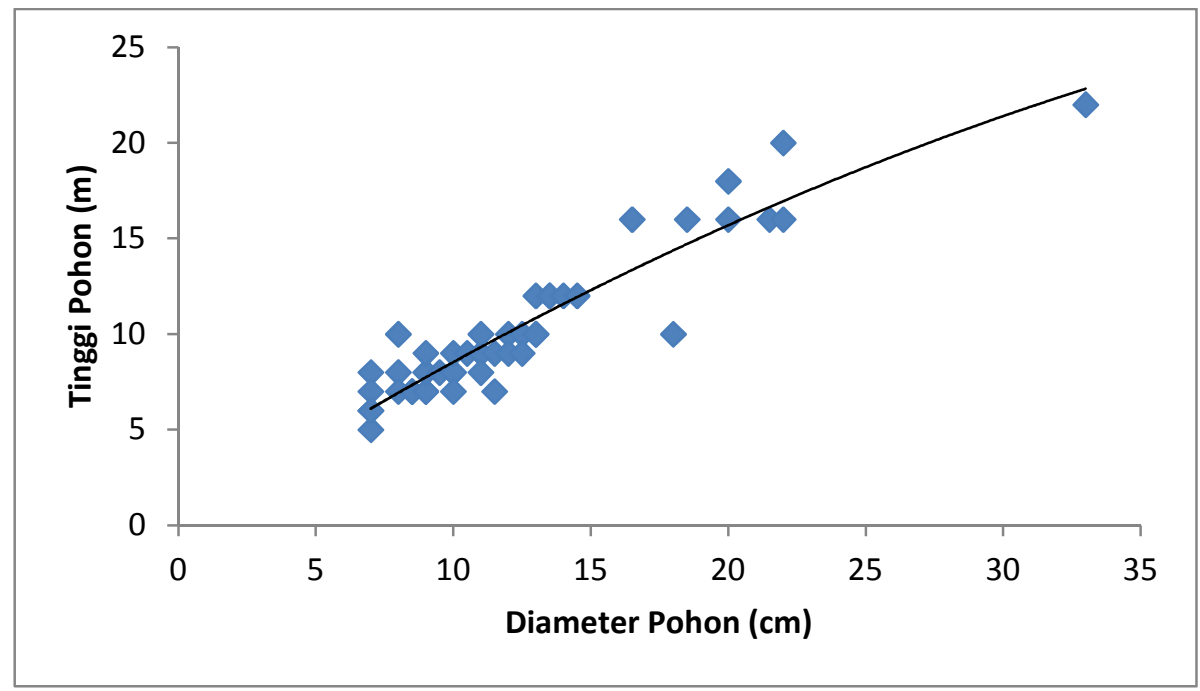

Sumber: diolah dari data primer.

Gambar 3. Model regresi hubungan tinggi pohon dengan diameter batang (dbh) tengkawang tungkul merah (S. stenoptera) di lokasi penelitian.

Figure 3. Regression model of the correlation between height and stem diameter (dbh) of tengkawang tungkul merah (S. stenoptera) in research location.

Ditinjau dari nilai galat baku (SE), kedua model ini cukup memenuhi syarat ketelitian dengan nilai masing-masing galat baku (SE) adalah $2,13 \%$ untuk tengkawang tungkul putih dan $1,39 \%$ pada tengkawang tungkul merah. Seperti yang telah dikemukakan oleh Prodan (1965) bahwa suatu persamaan regresi pendugaan yang menggunakan satu peubah maka galat baku maksimum yang dapat ditenggang adalah $20 \%$ dan apabila menggunakan dua peubah maka tenggangnya sebesar $25 \%$.

Untuk menguji tingkat signifikansi keeratan hubungan tinggi pohon dan diameter pohon dilakukan analisis varian (Anova), seperti yang tersaji pada Tabel 4 berikut ini. 
Tabel 4. Analisis varian hubungan tinggi pohon dan diameter batang (dbh) pada tegakan tengkawang tungkul putih (S. macrophylla) dan tungkul merah (S. stenoptera) di lokasi penelitian.

Table 4. Analysis of variance on the correlation between height and stem diameter (dbh) of tengkawang tungkul putih (S. macrophylla) and tungkul merah (S. stenoptera) in research location.

\begin{tabular}{|c|c|c|c|c|c|}
\hline $\begin{array}{l}\text { Variabel } \\
\text { (Variable) }\end{array}$ & $\begin{array}{c}\text { Derajat Bebas } \\
\text { (Degree of Freedom) }\end{array}$ & $\begin{array}{l}\text { Jumlah Kuadrat } \\
\text { (Sum of Square) }\end{array}$ & $\begin{array}{l}\text { Rataan Kuadrat } \\
\text { (Mean of Square) }\end{array}$ & Fhit & $\begin{array}{l}\text { Ftab } \\
95 \%\end{array}$ \\
\hline \multicolumn{6}{|c|}{ Tengkawang Tungkul Putih } \\
\hline - Regresi & 2 & 3633.835 & 1816.918 & 401.5518 & 6.8888 \\
\hline - Sisa & 179 & 809.9285 & 4.52474 & & \\
\hline - Jumlah & 181 & 4443.764 & & & \\
\hline \multicolumn{6}{|c|}{ Tengkawang Tungkul Merah } \\
\hline - Regresi & 2 & 599.0535 & 299.5267 & 155.2245 & 1.1666 \\
\hline - Sisa & 44 & 84.90395 & 1.929635 & & \\
\hline - Jumlah & 46 & 683.9574 & & & \\
\hline
\end{tabular}

Sumber: diolah dari data primer.

Hasil analisis varians dari kedua jenis tengkawang menunjukkan bahwa besarnya nilai $\mathrm{F}$ hitung lebih besar dari $\mathrm{F}$ tabel $95 \%$ yang mengindikasikan bahwa keduanya memiliki hubungan yang sangat signifikan, dimana dengan bertambahnya diameter akan berpengaruh juga terhadap pertumbuhan dari tinggi pohon tersebut. Dengan demikian, diharapkan kedepannya model persamaan alometrik ini dapat membantu para praktisi kehutanan dalam menghitung potensi tegakan tengkawang dalam suatu unit tanaman hutan, tanpa kesulitan lagi untuk mengukur tinggi pohon dari tegakan tengkawang tersebut.

\section{Hubungan Diameter Tajuk dan Diameter Batang}

Model regresi yang digunakan untuk hubungan diameter tajuk dan diameter batang (dbh) pada kedua jenis tengkawang adalah tipe regresi power, seperti yang tersaji pada Gambar 4 dan 5 berikut ini. Model persamaan regresi atau allometrik yang dihasilkan dari hubungan diameter tajuk dengan diameter batang untuk kedua jenis tengkawang tersebut, adalah sebagai berikut :

$$
\begin{aligned}
& \mathrm{DT}_{\mathrm{tp}}=0,7174+0,4360 \mathrm{~d}-0,0045 \mathrm{~d}^{2} \\
& \mathrm{DT}_{\mathrm{tm}}=3.3287 \mathrm{~d}^{0.2327} \\
& \text { dimana : }
\end{aligned}
$$

$\mathrm{DT}_{\mathrm{tp}}$ : Diameter tajuk tengkawang tunggul putih $(\mathrm{m})$

$\mathrm{DT}_{\mathrm{tm}}$ : Diameter tajuk tengkawang tunggul merah (m)

d : Diameter batang $(\mathrm{dbh})(\mathrm{cm})$

Dari Gambar 4 dan 5 menunjukan bahwa analisa regresi hubungan antara diameter tajuk dan diameter batang pada kedua jenis tengkawang menunjukan hubungan yang cukup erat atau tidak berbeda nyata. Persamaan hubungan kedua variabel dengan kedua jenis tengkawang mempunyai nilai koefisien determinasi $\left(\mathrm{R}^{2}\right)$ sebesar 0,5172 untuk tengkawang tungkul putih dan 0,0658 pada tengkawang tungkul merah.

Selain itu tingkat ketelitian dari hubungan antara diameter tajuk dan diameter batang dari kedua model persamaan regresi tersebut, dapat juga ditinjau dari nilai galat baku atau standard error (SE), dimana masing-masing sebesar $1,7739(1,77 \%)$ untuk tengkawang tungkul putih dan $0,322(0,32 \%)$ pada tengkawang tungkul merah. Nilai galat baku (SE) tersebut dapat dikatakan bahwa kedua persamaan regresi yang diperoleh cukup memenuhi syarat ketelitian.

Walaupun bila ditinjau dari nilai koefisien korelasi (R) antara diameter tajuk dan diameter batang pada kedua model tersebut memiliki perbedaan yang cukup signifikan, yaitu 0,7192 
untuk tengkawang tungkul putih dan 0,256 untuk tengkawang tungkul merah.

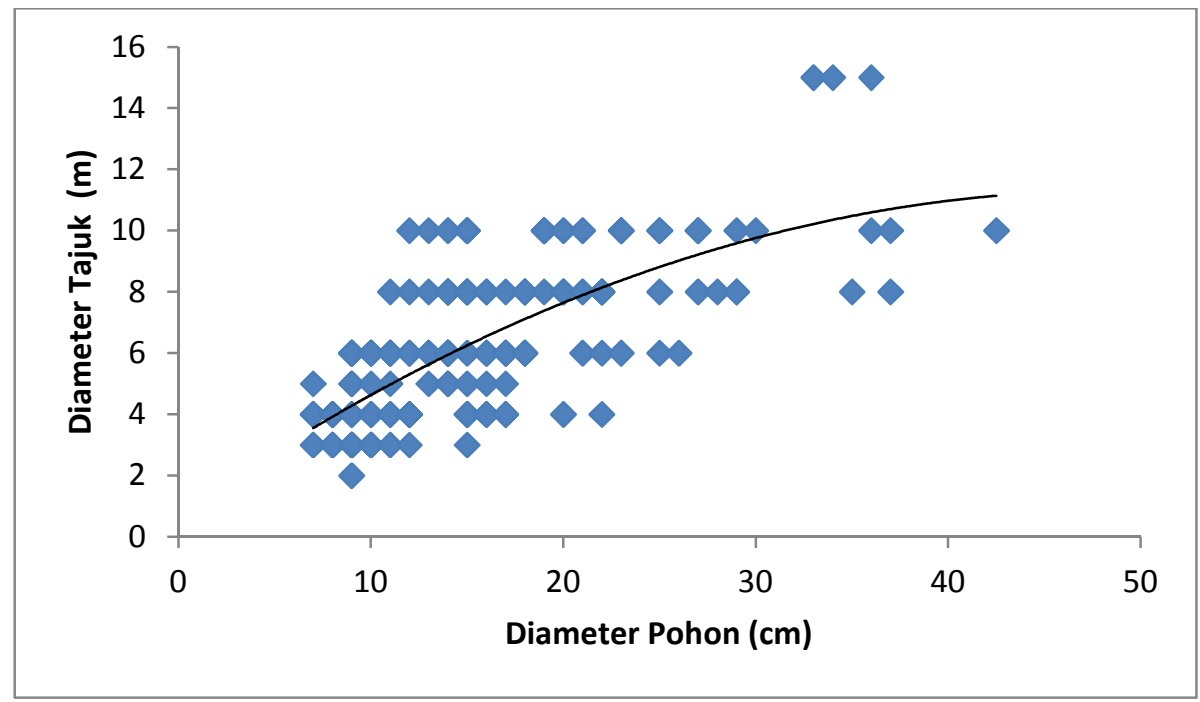

Sumber: diolah dari data primer.

Gambar 4. Model regresi hubungan diameter tajuk dengan diameter batang (dbh) tengkawang tungkul putih (S. macrophylla) di lokasi penelitian.

Figure 4. Regression model of the correlation between crown diameter and stem diameter (dbh) of tengkawang tungkul putih (S. macrophylla) in research location.

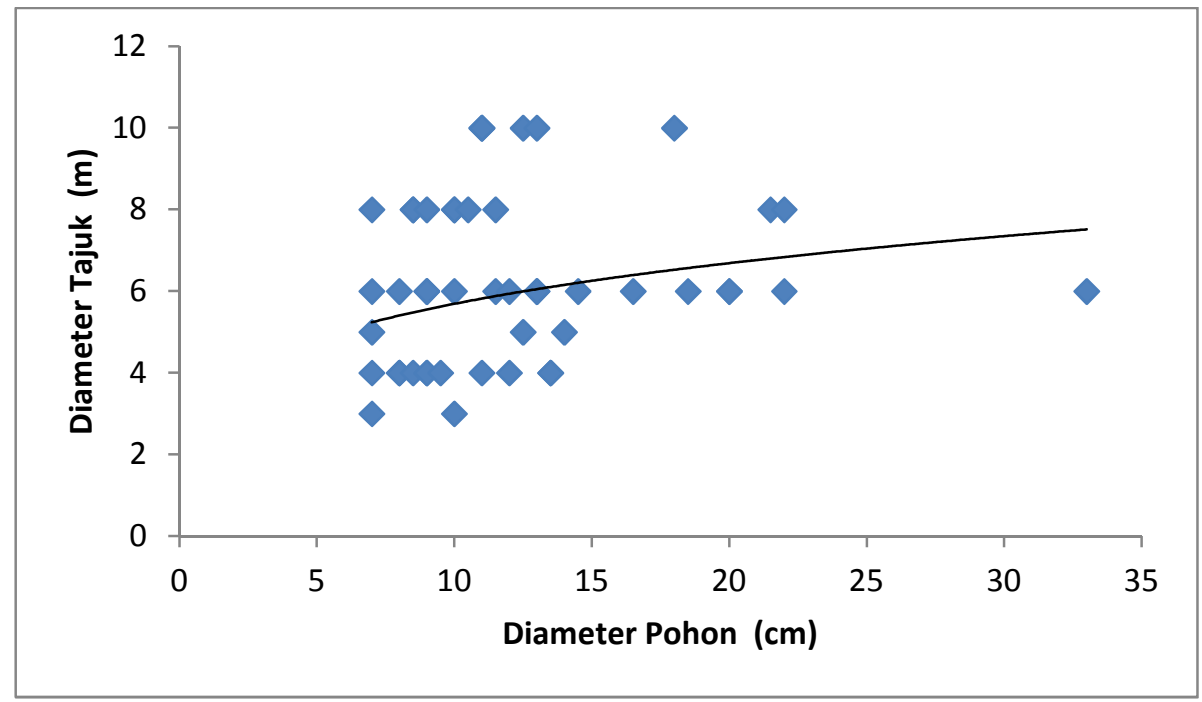

Sumber: diolah dari data primer.

Gambar 5. Model regresi hubungan diameter tajuk dengan diameter batang (dbh) tengkawang tungkul merah (S. stenoptera) di lokasi penelitian.

Figure 5. Regression model of the correlation between crown diameter and stem diameter (dbh) of tengkawang tungkul putih (S. stenoptera) in research location.

Hal ini tetap menunjukkan bahwa hubungan antara diameter tajuk dengan diameter batang setinggi dada adalah nyata, dimana lebih dari $25 \%$ dan $70 \%$ keragaman

diameter batang dapat menerangkan keragaman diameter tajuk. Hal ini mengindikasikan bahwa di setiap unit hutan tanaman tengkawang tungkul (Shorea spp.), keragaman diameter 
tajuk pohon dapat diterangkan oleh keragaman diameter batangnya.

Untuk menguji tingkat signifikansi keeratan hubungan diameter tajuk dan diameter batang dilakukan analisis varian (Anova), seperti yang tersaji pada Tabel 5 berikut ini.

Hasil analisis varian dari kedua jenis tengkawang menunjukkan bahwa besarnya nilai $\mathrm{F}$ hitung lebih besar dari $\mathrm{F}$ tabel $95 \%$ yang mengindikasikan bahwa keduanya memiliki hubungan yang signifikan, dimana dengan bertambahnya diameter akan berpengaruh juga terhadap pertumbuhan dari tajuk pada pohon tersebut. Seperti yang telah dilaporkan oleh
Sumarna (2008) menyebutkan bahwa pada pohon induk gaharu hasil uji Anova dan hasil uji beda antar kelas diameter batang dengan luas tajuk mempunyai saling keterkaitan yang signifikan diantara keduanya dan berpengaruh terhadap potensi permudaan alam. Dengan demikian, diharapkan model persamaan alometrik ini dapat membantu para praktisi kehutanan dalam memprediksi produksi buah pada setiap tegakan tengkawang dalam satuan unit hutan tanaman, tanpa mengalami kesulitan lagi untuk mengukur luas atau diameter dari tajuk tegakan tersebut.

Tabel 5. Analisis varian hubungan diameter tajuk dan diameter batang (dbh) pada tegakan tengkawang tungkul putih (S. macrophylla) dan tungkul merah (S. stenoptera) di lokasi penelitian.

Table 5. Analysis of variance on the correlation between crown diameter and stem diameter (dbh) of tengkawang tungkul putih (S. macrophylla) and tungkul merah (S. stenoptera) in research area.

\begin{tabular}{|c|c|c|c|c|c|}
\hline $\begin{array}{l}\text { Variabel } \\
\text { (Variable) }\end{array}$ & $\begin{array}{c}\text { Derajat Bebas (Degree } \\
\text { of Freedom) }\end{array}$ & $\begin{array}{l}\text { Jumlah Kuadrat } \\
\text { (Sum of Square) }\end{array}$ & $\begin{array}{l}\text { Rataan Kuadrat } \\
\text { (Mean of Square) }\end{array}$ & Fhit & $\begin{array}{l}\text { Ftab } \\
95 \%\end{array}$ \\
\hline \multicolumn{6}{|l|}{ Tungkul Putih } \\
\hline - Regresi & 2 & 603.5894 & 301.7947 & 95.90314 & 4.9222 \\
\hline - Sisa & 179 & 563.2897 & 3.14687 & & \\
\hline - Jumlah & 181 & 1166.879 & & & \\
\hline \multicolumn{6}{|l|}{ Tungkul Merah } \\
\hline - Regresi & 1 & 0.328 & 0.328 & 3.169 & 0.082 \\
\hline - Sisa & 45 & 4.654 & 0.103 & & \\
\hline - Jumlah & 46 & 4.982 & & & \\
\hline
\end{tabular}

Sumber: diolah dari data primer.

\section{KESIMPULAN}

Model persamaan regresi yang dapat dipergunakan untuk menduga tinggi pohon pada kedua jenis tengkawang adalah $\mathrm{T}_{\mathrm{tp}}=-2,2697+$ $1,2711 \mathrm{~d}-0,0162 \mathrm{~d}^{2}$ untuk jenis tengkawang tungkul putih dan $\mathrm{T}_{\mathrm{tm}}=-0,0803+0,9334 \mathrm{~d}-$ $0,0072 \mathrm{~d}^{2}$ untuk jenis tengkawang tungkul merah. Sedangkan model persamaan regresi yang dapat dipergunakan untuk menduga diameter tajuk pada kedua jenis tengkawang adalah $\mathrm{DT}_{\mathrm{tp}}=0,7174+0,4360 \mathrm{~d}-0,0045 \mathrm{~d}^{2}$ untuk jenis tengkawang tungkul putih dan $\mathrm{DT}_{\mathrm{tm}}$ $=3.3287 \mathrm{~d}^{0.2327}$ untuk jenis tengkawang tungkul merah. Adanya hubungan yang erat atau saling signifikan antara tinggi pohon dan diameter tajuk dengan diameter pohon (dbh), maka dalam kegiatan inventarisasi hutan tanaman tengkawang (Shorea spp) seperti pengukuran tinggi dan diameter tajuk dapat dieliminir dengan hanya mengukur diameter pohon setinggi dada (dbh).

\section{DAFTAR PUSTAKA}

BPS Kab. Sanggau. 2010. Kabupaten Sanggau Dalam Angka 2010. Badan Pusat Statistik Kabupaten Sanggau.

Buba, T. 2012. Prediction Equations for Estimating Tree Height, Crown Diameter, Crown Height and Crown Ratio of Parkia biglobosa in The Nigerian Guinea Savanna. African Journal of Agricultural Research Vol.7 No.49, Hal.6541-6543, 27 Desember 2012. 
Davis, L.S and K. N. Jhonson. 1987. Forest Management. Mc Graw-Hill Book Company. New York.

Huang, S., D. Price and S. J. Titus. 2000. Development of Ecoregion-Based Height-Diameter Models for White Spruce in Boreal Forests. Forest Ecology and Management Vol.129, Hal.125-141.

Husch, B., C. I. Miller and T. W. Beers. 1972. Forest Mensuration. Second Edition. The Ronald Press Company. New York.

Prodan, M. 1965. Forest Biometric. Perganon. OxfordLondon.

Siswanto, B.E. dan R. Imanuddin. 2008. Model Pendugaan Isi Pohon Agathis loranthifolia Salisb di Kesatuan Pemangkuan Hutan Kedu Selatan, Jawa Tengah. Jurnal Penelitian Hutan dan Konservasi Alam Vol.V No.5 Hal.485-496, 2008. Bogor.

Sonmez, T. 2009. Diameter at Breast Height - Crown Diameter Prediction Models for Picea orientalis. African Journal of Agri5cultural Research Vol.4 No.3, Hal.215-219, March 2009.
Sumarna, Y. 2008. Pengaruh diameter dan luas tajuk pohon induk terhadap potensi permudaan alam tingkat semai tumbuhan penghasil gaharu jenis karas (Aquilaria malaccensis Lamk). Jurnal Penelitian Hutan dan Konservasi Alam Vol.V No.1 Hal.21-27, 2008. Bogor.

Suyana, A. dan Abdurachman. 2006. Kondisi tegakan Shorea leprosula Miq. umur 13 tahun pada berbagai jarak tanam di KHDTK Sebulu, Kabupaten Kutai Kartanegara, Kalimantan Timur. Prosiding Seminar Bersama Hasil-hasil Penelitian. Balai Litbang Kehutanan Kalimantan. Balitbang Hutan Tanaman, Loka Litbang Satwa Primata. Samarinda.

Suyana, A. dan Abdurachman. 2011. Kondisi tegakan meranti tembaga (Shorea leprosula Miq.) di kawasan bekas kebakaran Samboja, Kalimantan Timur. Junal Penelitian Dipterokarpa Vol.5 No.1, Juni 2011. Balai Besar Penelitian Dipterokarpa. Samarinda.

Winarni I., E.S. Sumadiwangsa dan D. Setyawan 2005. Beberapa Catatan Pohon Penghasil Biji. Info Hasil Hutan Vol. 11 No.1. Puslitbang Hasil Hutan. Bogor. 